\title{
Die Oper in Spanien und Portugal
}

Der Entwicklung einer eigenständigen Oper in Spanien stand, abgesehen von den engen politischen und kulturellen Beziehungen des Landes zu Italien, ähnlich wie in England die hohe Bedeutung des gesprochenen Dramas und sein Ansehen im Wege. Zwar spielte die Musik darin, wie auch im Drama Shakespeares, als Zutat eine nicht unwesentliche Rolle, am Drama selbst aber hatte sie keinen Anteil. Trotzdem entwickelte sich auf diesem Boden im 17. Jahrhundert unter Beteiligung der beiden großen Dramatiker Lope de Vega (1562-1632) und Calderon de la Barca (1600-1681) eine eigene, dramatisch zunächst bescheidenere, mehr singspielhafte Gattung, die "Zarzuela" (so genannt nach einem Palast dieses Namens bei Madrid, in dem diese Stücke zunächst aufgeführt wurden ${ }^{1}$, die sich bald in Gestalt festlicher, bald mehr volkstümlicher Darbietungen großer Beliebtheit erfreuten. Eines der frühesten Beispiele dieser Gattung war LA SELVA SIN AMOR (Der lieblose Wald) von Lope de Vega (1629), zu dem aber keine Musik erhalten ist. Calderon strebte mit seinem Komponisten Juan Hidalgo zusammen mehr nach einer opernhaften Einkleidung seiner Dramen, verschmähte aber daneben auch die anspruchslosere zweiaktige Zarzuela nicht. Sie war bei ihm vorwiegend heroisch-mythologischen Inhalts, nahm aber im Laufe des 18. Jahrhunderts textlich wie musikalisch mehr und mehr einen volkstümlichen, d. h. nationalen Charakter an. Dazu kamen in der zweiten Hälfte des Jahrhunderts weitere volkstümliche Gattungen wie die "Sainete“ und vor allem die „Tonadilla“, eine Art von komischer Kurz-Oper im Stil der italienischen Intermezzi oder auch der opéra comique, die auch als $Z$ wischenaktsmusiken für gesprochene Komödien verwendet werden konnten und sich bis in den Anfang des 19. Jahrhunderts hielten - dann fiel ihre musikalische Volkstümlichkeit allerdings dem ständig zunehmenden Einfluß der beiden fremden Gattungen zum Opfer. Hingegen erfuhr um die Mitte des Jahrhunderts die Zarzuela, nunmehr dreiaktig, im Schaffen von Komponisten wie Francisco Asenjo Barbieri (1823-1894), Joaquín Gaztambide (1822-1870), Emilio Arrieta (1823-1894) und anderen unter der Bezeichnung „Zarzuela grande“ eine nationale Wiederbelebung. Diese führte sie in die Nähe der ernsten Oper, von der sich ihr heiteres, einaktiges Gegenstück, das spritzige „genero chico", wirkungsvoll abhob.

So herrschte im 19. Jahrhundert ein reges Leben auf den Opernbühnen von Madrid, von einer großen Zahl einheimischer Komponisten getragen und zwischen eigener Prägung und fremden Einflüssen schwankend. Zu ihnen gesellte sich nach der Jahrhundert-Mitte auf Anregung des als Kenner des spanischen wie des ausländischen Musikwesens, als Musikforscher wie als Musiker gleich bedeutenden Felipe Pedrell (1841-1922) auch noch der Einfluß des Wagnerschen Werkes. $\mathrm{Zu}$ Pedrells Schülern gehörten die auch als Opernkomponisten angesehenen Isaac Albeniz (1860-1909), Enrique Granados (1867-1916) und Manuel de Falla (1876-1946). Auf diese Weise halten sich hier die „spanische Oper“ und die „Oper in Spanien“ ungefähr die Waage, während in Portugal das letztere, eine - sehr rege - Opernpflege, überwog.

1 Vgl. Grout, A short history of opera, S. 270. 